\title{
BMJ Open Seroprevalence of COVID-19 IgG antibodies among healthcare workers of Pakistan: a cross-sectional study assessing exposure to COVID-19 and identification of high-risk subgroups
}

\author{
Hijab Batool (10 , ${ }^{1}$ Omar Chughtai, ${ }^{2}$ Muhammad Dilawar Khan, ${ }^{1}$ \\ Akhtar Sohail Chughtai, ${ }^{2}$ Shakeel Ashraf, ${ }^{2}$ Muhammad Jamil Khan ${ }^{2}$
}

To cite: Batool H, Chughtai 0 , Khan MD, et al. Seroprevalence of COVID-19 IgG antibodies among healthcare workers of Pakistan: a cross-sectional study assessing exposure to COVID-19 and identification of high-risk subgroups. BMJ Open 2021;11:e046276. doi:10.1136/ bmjopen-2020-046276

- Prepublication history for this paper is available online. To view these files, please visit the journal online (http://dx.doi. org/10.1136/bmjopen-2020046276).

Received 04 November 2020 Accepted 28 July 2021

Check for updates

(c) Author(s) (or their employer(s)) 2021. Re-use permitted under CC BY-NC. No commercial re-use. See rights and permissions. Published by BMJ.

${ }^{1}$ Chemical Pathology, Chughtai Institute of Pathology, Lahore, Pakistan

${ }^{2}$ Chughtai Institute of Pathology, Lahore, Pakistan

Correspondence to

Dr Hijab Batool;

dr.hijabbatool@cll.edu.pk

\section{ABSTRACT}

Objective In this study, we aimed to find the seroprevalence of healthcare workers (HCWs) of Pakistan involved in the treatment and care of patients with COVID-19.

Setting This was a cross-sectional study and total of 15 $000 \mathrm{HCWs}$ involved in providing services and care to the patients with COVID-19 were randomly selected from all over Pakistan.

Participants Informed consent was taken from all participants and were included according to inclusion and exclusion criteria. All testing was done on serum samples for the qualitative detection of SARS-CoV-2 IgG antibodies using Abbott Chemiluminescent microparticle immunoassay. An index of 1.4 was used as a cut-off to mark reactive and non-reactive cases. SPSS V.23.0 was used for data analysis.

Outcome Immune status of the study population depicting seroprevalence among HCWs.

Results Out of all the candidates, majority of the HCWs were men $(61.9 \%)$ and were doctors $(62.4 \%)$. The mean age of participants was 32.8 years (SD 8.7) and majority were asymptomatic (51.8\%). In this study, $33 \%$ of the HCWs were reactive for SARS-CoV-2 IgG antibody. Around $44 \%$ of the reactive cases were asymptomatic. The symptoms more significantly associated with seropositivity were: fever (OR 1.31; 95\% $\mathrm{Cl} 1.16$ to 1.48), headache (OR 2.43; $95 \% \mathrm{Cl} 2.16$ to 2.73), cough and shortness of breath (OR 2.10; $95 \% \mathrm{Cl} 1.91$ to 2.31), loss of sense of smell or taste (OR 3.70; 95\% Cl 3.29 to 4.17) ( $<<0.001)$. Factors which showed significant association with the presence of antibodies were professional category (absolute risk (AR) 0.09 ; OR 1.46; $95 \% \mathrm{Cl} 1.36$ to 1.56 ), availability of protective masks (AR 0.02; OR 0.90; $95 \% \mathrm{Cl} 0.84$ to 0.96 ), safety goggles (AR $0.02 ; 0 R \quad 0.90 ; 95 \% \mathrm{Cl} 0.84$ to 0.97 ) and living arrangements (AR 0.03; OR 1.12; 95\% Cl 1.04 to 1.20) $(p<0.05)$.

Conclusion Our study showed a high seropositivity of HCWs dealing with patients with COVID-19 in Pakistan revealing significant association with professional category, nature of work place and precautions taken while performing duties.

\section{Strengths and limitations of this study}

- First study in the country to report seroprevalence of COVID-19 IgG among healthcare workers.

- Health policy makers can use the findings of our study to make better strategies.

- High-risk subgroups of healthcare workers and high-risk health departments were identified.

- Only the antibody against the N protein of SARSCoV-2 was assessed.

- Subjects were not followed up to understand the duration of seropositivity.

\section{INTRODUCTION}

COVID-19 associated with SARS-CoV-2 has emerged as a pandemic. Since the identification of initial cases of this atypical pneumonia, there has been an exponential increase in the number of cases worldwide. ${ }^{1}$ Some of the few causes of this exponential increase in number include high-transmission rate especially among the asymptomatic cases, poor healthcare strategies and limited knowledge about the COVID-19. ${ }^{2}$ Subclinical or asymptomatic cases are one of the major challenges in this pandemic as it is presumed that these cases can play a major role in infection spread while remaining undiscovered in the community.

As of 22 August 2020, confirmed cases of COVID-19 in Pakistan are 292150 with 731 critical cases and 275317 recoveries. ${ }^{3}$ The correct estimate of the spread of COVID-19 in Pakistan is still not clear, posing a huge challenge to healthcare agencies of Pakistan. Most of the mildly symptomatic, asymptomatic cases and the cases belonging to areas of limited resources who are not tested via government healthcare agencies can easily be missed and the actual number of the affected individuals remains unidentified. The risk of 
COVID-19 among healthcare workers (HCWs) of Pakistan is still not clear. Studies have revealed that $9 \%$ of the individuals in Italy and $26 \%$ of the individuals in Spain who were tested positive for COVID-19 via reverse transcriptase PCR (RT-PCR) in prevalence studies were HCWs. ${ }^{4}$ In accordance with other coronaviruses, HCWs-associated transmission of COVID-19 appears to play a major role in infection spread. One prevalence study suggested that more than $40 \%$ of the diagnosed cases of COVID-19 were assumed to have been acquired from HCWs. ${ }^{6}$

Majority of the SARS-CoV-2 infected cases remain asymptomatic and the virus may be far more widely distributed than experts may believe. ${ }^{7}$ During the first 21 days of SARS-CoV-2 infection, reasonable increases are observed in virus-specific IgM and IgG titers. ${ }^{8}$ According to one estimate, herd immunity can be ensured if around $50 \%-67 \%$ of the population develops immunity against SARS-CoV-2. ${ }^{9}$ Seroconversion is determined by analysing antibody status of the population. ${ }^{9}{ }^{10}$ Serosurveillance of HCWs is an important indicator of COVID-19 spread as they fall in the category of population which is most exposed to SARS-CoV-2 infection.

In this study, we aimed to find the seroprevalence of HCWs of Pakistan involved in the management and care of patients with COVID-19. This study will help to identify the high-risk subgroups of HCWs, high-risk departments and different factors associated with the risk of SARS-CoV-2 infection.

\section{METHODOLOGY}

\section{Subject selection}

A total of 15000 HCWs both men and women were randomly selected for this study from all over Pakistan. A list of healthcare centres who were authorised to treat and diagnose patients with COVID-19 was issued by government officials of Pakistan and only the HCWs involved in providing services and care in these centres were involved in this study. All doctors, nurses / para medical staff and medical laboratory technologists in Pakistan are registered in Pakistan Medical Council health registry, Pakistan Nursing Council and Medical Laboratory Technology Association of Pakistan, respectively. The registration number of all healthcare professionals was confirmed from the authorities before including them in the study. The HCWs with no interaction with patients with COVID-19 (either direct contact or dealing with patient samples) or the workers who were not present on duty in the last one month from the date of commencement of study were excluded. Moreover, HCWs who were already involved in some clinical trials of COVID-19 were not involved in the study. All participants were explained the objective of the study and the HCWs showing active signs and symptoms compatible with COVID-19 were not involved in the study as they might be a risk to the team members of the laboratory taking samples and most probably be in the initial phase of the infection in which IgG is not likely to be present. After taking a written informed consent, the participants were asked to fill a questionnaire in which they had to mention their age, gender, professional category, place and nature of duty, kind of personal protective equipment (PPE) provided to them, presence of sign and symptoms and living arrangement. A $3 \mathrm{~mL}$ random blood sample was collected from each participant to assess immunological response. Sample was collected by trained phlebotomist wearing appropriate PPE. Our laboratory centres are located throughout the country; therefore, our own designated sample collection team was sent to collect samples from all the participants. No local occupational health nurses were involved in sample collection. All the samples collected were transported immediately to the laboratory where those were centrifuged at $5000 \mathrm{~g}$ for $5 \mathrm{~min}$ to separate sera for analysis.

\section{Patient and public involvement}

HCWs involved in providing services and care to the patients with COVID-19 were involved in the design and conduct of this study. Discussion sessions were arranged with a group of HCWs to discuss the feasibility of the project, designing proforma, outcome measures and sample collection procedure. This discussion group considered participants' priorities and preferences while designing the study. All the participants will be informed about the results of the study after publication through phone calls and lab reports posted if desired by the study participants.

\section{Laboratory analysis}

Analysis was done on serum samples for the qualitative detection of SARS-CoV-2 IgG antibodies using Food and Drug Administration (FDA) approved Abbott Chemiluminescent Microparticle Immunoassay on Abbott Alinity Ci. This is an Emergency Use Authorization-granted assay with a specificity of $99.6 \%$ and sensitivity of $96.7 \%$ for COVID-19 confirmed cases with more than 14 days of symptoms. An index of 1.4 was used as a cut-off to mark reactive and non-reactive cases. Cases with results greater than the cut-off value were marked as reactive and those with results less than the cut-off were declared as nonreactive for SARS-CoV-2 IgG antibodies.

\section{Statistical analysis}

SPSS V.23.0 was used for data analysis. Seroprevalence was calculated and associations between variables of the study were tested via $\chi^{2}$ and Fisher's exact test using $p$ value $<0.05$ as significant. Relative risk was expressed as OR.

\section{RESULTS}

\section{Baseline characteristics of the participants}

A total of 16882 HCWs were randomly approached for the survey between 1 July 2020 and 20 July 2020. Of 
Table 1 Baseline characteristics of healthcare workers participating in the study

\begin{tabular}{|c|c|c|c|}
\hline Groups & Subgroups & Total number & Percentages \\
\hline \multirow[t]{2}{*}{ Gender } & Male & 9282 & 61.9 \\
\hline & Female & 5718 & 38.1 \\
\hline \multirow[t]{2}{*}{ Category } & Doctor & 9362 & 62.4 \\
\hline & Nurse & 2260 & 15.1 \\
\hline \multirow[t]{5}{*}{ Place of duty } & General ward & 6327 & 42.2 \\
\hline & OPD/clinic & 4010 & 26.7 \\
\hline & COVID-19 quarantine centre & 291 & 1.9 \\
\hline & COVID-19 isolation ward & 2820 & 18.8 \\
\hline & HDU/ICU & 1445 & 9.6 \\
\hline \multirow[t]{2}{*}{ Tyvek suits } & Not available & 7784 & 51.9 \\
\hline & Available & 7216 & 48.1 \\
\hline \multirow[t]{2}{*}{ Face shield } & Not available & 9518 & 63.5 \\
\hline & Available & 5482 & 36.5 \\
\hline \multirow[t]{2}{*}{ Safety goggles } & Not available & 10299 & 68.7 \\
\hline & Available & 4701 & 31.3 \\
\hline \multirow[t]{2}{*}{ Gloves } & Not available & 3849 & 25.7 \\
\hline & Available & 11151 & 74.3 \\
\hline Experienced generalised fatigue only & & 972 & 6.5 \\
\hline \multirow[t]{2}{*}{ Living arrangement } & Living in hostel/single family & 6089 & 40.5 \\
\hline & Living with family & 8911 & 59.5 \\
\hline
\end{tabular}

HDU, High Dependency Unit; ICU, intensive care unit; OPD, Out Patient Department.

these, 1672 were excluded from the survey on the basis of exclusion criteria, 210 fulfilled the inclusion criteria but refused to participate and 15000 cases were selected with a total participation rate of $88.8 \%$. These HCWs included doctors, nurses and paramedical staff directly involved in providing medical care to the patients with COVID19. Out of all the cases, majority of the HCWs were men $(61.9 \%)$ and were doctors $(62.4 \%)$ followed by paramedical staff (22\%). The mean age of participants was 32.8 years \pm 8.7 and majority were asymptomatic $(51.8 \%)$. The nature of PPE provided to HCWs, the place of duty, living arrangements along with some other characteristics of the participating HCWs are mentioned in table 1.

\section{Seroprevalence of SARS-CoV-2 IgG antibodies among the HCWs}

In this study, $33 \%$ of the HCWs were reactive for SARS-CoV-2 IgG antibody and maximum percentage of HCWs (46\%) showing seropositivity was between 23 and 30 years of age. Out of all the tests conducted, maximum number of participants were from Punjab (10 943) followed by Khyber Pakhtunkhwa (2606) (figure 1). City wise seropositivity is given in figure 2. Among the reactive cases, $40 \%$ of the HCWs performed duties in general COVID-19 ward, 28\% were working in outpatient department receiving patients with COVID$19,20 \%$ in COVID-19 isolation and quarantine centres 


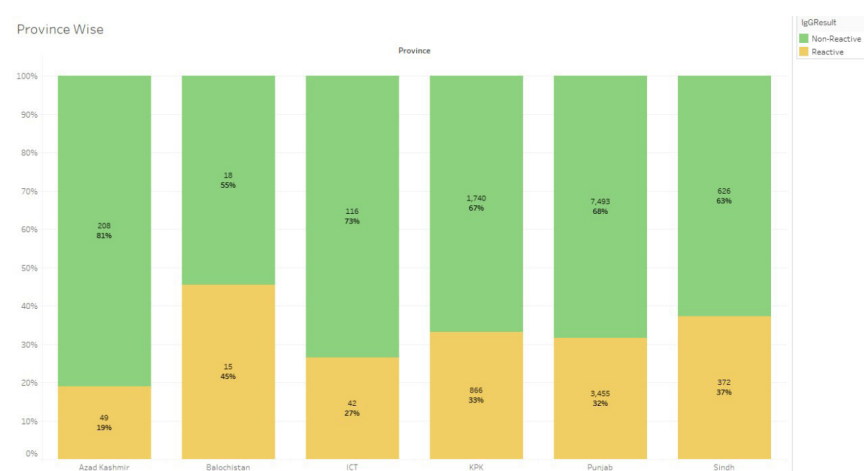

Figure 1 Total number of tests conducted in each Province of Pakistan and respective seropositivity.

and $10 \%$ were working in COVID-19 high dependency units with patients having severe symptoms requiring mechanical respiratory support.

Around 2223 (44\%) of the reactive cases were asymptomatic. The symptoms more significantly associated with seropositivity were: low grade fever only (OR 1.31; $95 \%$ CI 1.16 to 1.48), high grade fever with headache (OR 2.43; $95 \%$ CI 2.16 to 2.73 ), fever with cough and shortness of breath (OR 2.10; 95\% CI 1.91 to 2.31), Loss of sense of smell or taste only (OR 3.70; 95\% CI 3.29 to 4.17) $(p<0.001)$. Factors which showed significant association with the presence of antibodies were gender, professional category, availability of protective masks, safety goggles and living arrangements $(\mathrm{p}<0.05)$. Absolute risk (AR) and relative risk of different variables expressed in terms of OR are given in table 2.

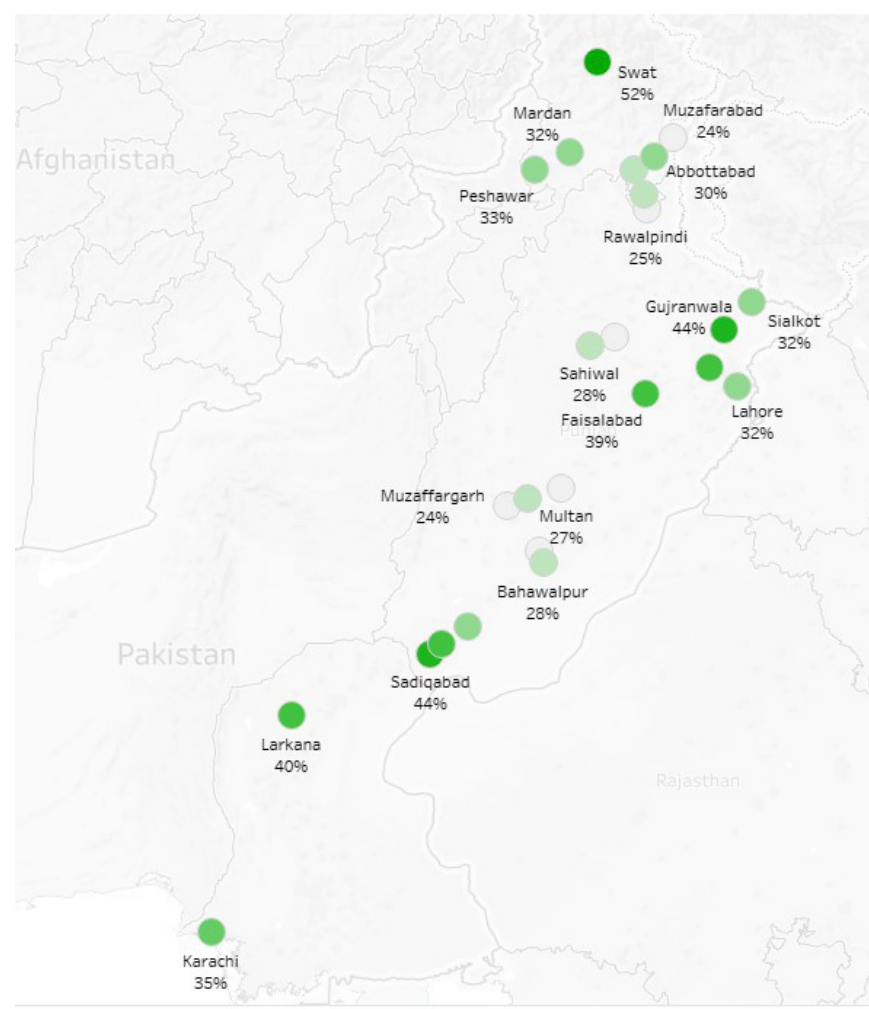

Figure 2 Seropositivity of healthcare workers in different cities of Pakistan.

\section{DISCUSSION}

Serosurveys are essential in the management of infectious diseases to assess the immunity in a population. ${ }^{11}$ This is the first study reporting SARS-CoV-2 IgG antibodies seroprevalence among HCWs in Pakistan who are the frontline warriors in this pandemic. Pakistan is a developing nation with limited medical resources and HCWs are not provided with all the necessary equipment to protect themselves from this deadly virus. In this study, we found a seropositivity of $33 \%$ among HCWs of Pakistan with highest seropositivity in the Punjab region of Pakistan with maximum disease burden. ${ }^{3}$ The association of antibodies with virus neutralisation, correlation of antibody titers with protection against re-infection and difference in immunological response of symptomatic and asymptomatic cases is still unclear. ${ }^{12}$ However, the role of serological assays in assessing the prevalence of COVID-19 in the community is unquestionable. ${ }^{13}$ We designed this study to investigate seroprevalence of SARS-CoV-2 IgG antibodies among the population involved in direct dealing with patients with COVID-19 (either the patients or direct dealing with patient samples) with FDA-approved assay having high analytical performance capable to identify IgG antibodies against N protein of the virus. ${ }^{14}$ The HCWs showing active signs and symptoms were excluded from the study to reduce the risk of exposure of laboratory staff collecting blood samples and also due to the probability of HCWs being present in acute phase of the infection when IgG is not developed enough to be detected by the assay. Given the fact that HCWs are at a very high risk of COVID-19, from our findings with a seropositivity of 33\% among HCWs, it can be assumed that Pakistani population is still far from reaching more than $60 \%$ herd immunity level that is required for community protection against the infection. ${ }^{15}$ Low OR of some of the PPE (like protective masks) might be due to the fact that despite of existence, the PPE was not being used properly or they were not available in adequate quantity.

To date, many studies have been conducted worldwide to unfold prevalence of SARS-CoV-2 IgG antibodies among HCWs. Screening of symptomatic HCWs has been done with the help of RT-PCR in some surveillance studies and it was found that almost $18 \%$ of the HCWs were infected by SARS-CoV-2. ${ }^{16}{ }^{17}$ Another screening study on asymptomatic HCWs revealed that $3 \%$ of the staff was SARS-CoV-2 positive by RT-PCR.$^{18}$ In one study, the authors speculated that frontline HCWs are more prone to be infected by the virus. Not only the health professionals who are working in the dedicated COVID-19 health facilities are expected to be exposed but also the workers who are performing duties in other specialties where patients with SARS-CoV-2 are admitted for other reasons. ${ }^{19}$ A study conducted on women admitted in labour room to give birth showed that $15 \%$ of the expecting mothers were SARS-CoV-2 positive and another study in old care home revealed $4 \%$ of the residents to be positive. ${ }^{20}{ }^{21} \mathrm{~A}$ recent seroprevalence study conducted in Denmark showed that $4 \%$ of the HCWs showed seropositivity against SARS-CoV-2 and the 


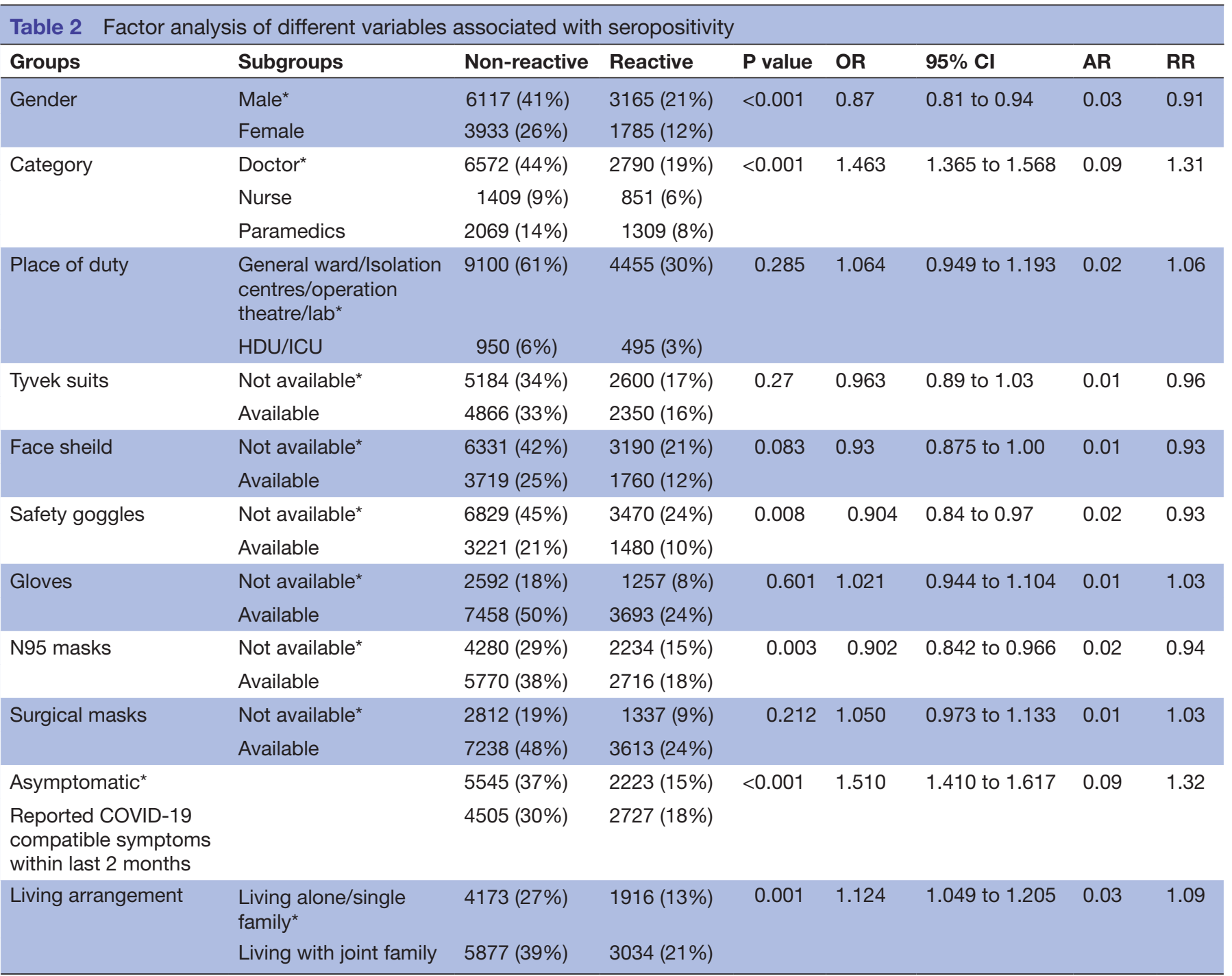

*The reference group for the OR is the first mentioned group.

$A R$, absolute risk; HDU, High Dependency Unit; RR, relative risk.

risk of viral infection was related to the level of exposure to the infected patients. ${ }^{22}$ This study also revealed that seroconversion was higher in male HCWs as compared with female HCWs but the authors attributed this finding to higher frequency of critical illness in men rather than higher susceptibility of infection in male gender. ${ }^{22}$ This finding is in accordance with our study in which male HCWs showed more frequent seroconversion as compared with female HCWs and seropositivity had an association with direct contact with the patients.

An Italian study found that $4.6 \%$ of the HCWs were seropositive, majority were men and low prevalence was found in asymptomatic cases. ${ }^{23}$ All these findings are in accordance with our study which yielded similar findings. Another study conducted at a large Spanish hospital found a seroprevalence of $9.3 \%$ in a random sample of healthcare professionals and the authors concluded that HCWs are at a higher risk to acquire SARS-CoV-2 infection from fellow workers or directly from the patients. ${ }^{24}$ Our study revealed that there is a significant association between presence and absence of PPE and seropositivity. Some studies suggest that seropositivity is attributable to institutional application of proper PPE use hospitals which prepared well before time for this pandemic had a lower infection rate among their HCWs. ${ }^{23} \mathrm{~A}$ special communication regarding risk assessment of HCWs performing duties at high-risk areas suggested that lack of understanding of the disease course, improper use of PPE, stress at work, unavailability of screening tests and lack of resources are the major factors leading to high rate of infection among this cohort. ${ }^{25}$ Our study has some limitations like only the antibody against the $\mathrm{N}$ protein was assessed, subjects were not followed up to understand the duration of seropositivity and protection from getting re-infected again.

\section{CONCLUSION}

This is a large-scale study conducted in all provinces of Pakistan showing a high seropositivity of HCWs dealing 
with patients with COVID-19. The seropositivity had significant association with place of duty, professional category and availability of PPE. This study can help healthcare policy makers of Pakistan to make better strategies to protect the frontline warriors in this pandemic.

\section{SUMMARY}

- Subclinical or asymptomatic cases can play a major role in SARS-CoV-2 transmission while remaining undiscovered in the community.

- HCWs fall in the category of population which is most exposed to SARS-CoV-2 infection.

- $33 \%$ of the HCWs were reactive for SARS-CoV-2 $\mathrm{IgG}$ antibody and $44 \%$ of the reactive cases were asymptomatic

- Our study revealed that there is a significant association between use of personal protective equipment, professional category, place of duty and seropositivity.

- This study can help healthcare policy makers of Pakistan to know to extent of infection among the HCWs and make better strategies.

\section{Twitter Muhammad Jamil Khan @jk99cs}

Contributors HB contributed to paper write-up, data collection and analysis, literature review. $\mathrm{OC}$ contributed to original concept, study design, supervision. MDK contributed to proof reading, approval, discussion. ASC contributed to proof reading and approval. SA contributed to data collection, statistical analysis. MJK contributed to data entry and analysis.

Funding Chughtai Lab, Lahore, Pakistan.

Map disclaimer The inclusion of any map (including the depiction of any boundaries therein), or of any geographic or locational reference, does not imply the expression of any opinion whatsoever on the part of BMJ concerning the legal status of any country, territory, jurisdiction or area or of its authorities. Any such expression remains solely that of the relevant source and is not endorsed by BMJ. Maps are provided without any warranty of any kind, either express or implied.

Competing interests None declared.

Patient and public involvement Patients and/or the public were involved in the design, or conduct, or reporting, or dissemination plans of this research. Refer to the Methods section for further details.

Patient consent for publication Not required.

Ethics approval Ethical approval was obtained by Institutional Review Board of Chughtai Institute of Pathology prior to initiation of the research work.

Provenance and peer review Not commissioned; externally peer reviewed.

Data availability statement All data relevant to the study are included in the article or uploaded as supplementary information. No additional data available.

Open access This is an open access article distributed in accordance with the Creative Commons Attribution Non Commercial (CC BY-NC 4.0) license, which permits others to distribute, remix, adapt, build upon this work non-commercially, and license their derivative works on different terms, provided the original work is properly cited, appropriate credit is given, any changes made indicated, and the use is non-commercial. See: http://creativecommons.org/licenses/by-nc/4.0/.

ORCID iD

Hijab Batool http://orcid.org/0000-0002-6155-9217
REFERENCES

1 Onder G, Rezza G, Brusaferro S. Case-Fatality rate and characteristics of patients dying in relation to COVID-19 in Italy. JAMA 2020;323:1775-6.

2 Cheng MP, Papenburg J, Desjardins M, et al. Diagnostic testing for severe acute respiratory syndrome-related coronavirus 2: a narrative review. Ann Intern Med 2020;172:726-34.

3 [Internet]. Covid.gov.pk, 2020. Available: http://covid.gov.pk/ [Accessed 22 Aug 2020].

4 Remuzzi A, Remuzzi G. COVID-19 and Italy: what next? Lancet 2020;395:1225-8.

5 [Internet]. Isciii.es, 2020. Available: https://www.isciii.es/ QueHacemos/Servicios/VigilanciaSaludPublicaRENAVE/Enfermed adesTransmisibles/Documents/INFORMES/Informes\%20COVID-19/ Informe\%20n\%C2\%BA\%2035.\%20Situaci\%C3\%B3n\%20de\% 20COVID-19\%20en\%20Espa\%C3\%B1a\%20a\%2017\%20de\% 20julio\%20de\%202020.pdf [Accessed 22 Aug 2020].

6 Wang D, Hu B, Hu C, et al. Clinical characteristics of 138 hospitalized patients with 2019 novel coronavirus-infected pneumonia in Wuhan, China. JAMA 2020;323:1061-9.

7 Day M. Covid-19: four fifths of cases are asymptomatic, China figures indicate. BMJ 2020;369:m1375.

8 Long Q-X, Liu B-Z, Deng H-J, et al. Antibody responses to SARSCoV-2 in patients with COVID-19. Nat Med 2020;26:845-8.

9 Omer SB, Yildirim I, Forman HP. Herd immunity and implications for SARS-CoV-2 control. JAMA 2020;324:2095-6.

10 Amanat F, Stadlbauer D, Strohmeier S, et al. A serological assay to detect SARS-CoV-2 seroconversion in humans. Nat Med 2020;26:1033-6.

11 Torres R, Rinder HM. Are SARS-CoV-2 serological tests safe right now? Am J Clin Pathol 2020;153:709-11.

12 Krammer F, Simon V. Serology assays to manage COVID-19. Science 2020;368:1060-1.

13 Sethuraman N, Jeremiah SS, Ryo A. Interpreting diagnostic tests for SARS-CoV-2. JAMA 2020;323:2249-51.

14 Bryan A, Pepper G, Wener MH, et al. Performance characteristics of the Abbott architect SARS-CoV-2 IgG assay and seroprevalence in Boise, Idaho. J Clin Microbiol 2020;58:JCM.00941-20.

15 Kwok KO, Lai F, Wei WI, et al. Herd immunity - estimating the level required to halt the COVID-19 epidemics in affected countries. $J$ Infect 2020;80:e32-3.

16 Tostmann A, Bradley J, Bousema T, et al. Strong associations and moderate predictive value of early symptoms for SARS-CoV-2 test positivity among healthcare workers, the Netherlands, March 2020. Euro Surveill 2020;25:2000508.

17 Keeley AJ, Evans C, Colton H, et al. Roll-out of SARS-CoV-2 testing for healthcare workers at a large NHS Foundation trust in the United Kingdom, March 2020. Euro Surveill 2020;25:2000433.

18 Rivett L, Sridhar S, Sparkes D, et al. Screening of healthcare workers for SARS-CoV-2 highlights the role of asymptomatic carriage in COVID-19 transmission. Elife 2020;9:e58728.

19 Hunter E, Price DA, Murphy E, et al. First experience of COVID-19 screening of health-care workers in England. Lancet 2020;395:e77-8.

20 Sutton D, Fuchs K, D'Alton M, et al. Universal screening for SARS-CoV-2 in women admitted for delivery. $N$ Engl J Med 2020;382:2163-4.

21 Roxby AC, Greninger AL, Hatfield KM, et al. Detection of SARSCoV-2 Among Residents and Staff Members of an Independent and Assisted Living Community for Older Adults - Seattle, Washington, 2020. MMWR Morb Mortal Wkly Rep 2020;69:416-8.

22 Iversen K, Bundgaard H, Hasselbalch RB, et al. Risk of COVID-19 in health-care workers in Denmark: an observational cohort study. Lancet Infect Dis 2020;20:1401-8.

23 Plebani M, Padoan A, Fedeli U, et al. SARS-CoV-2 serosurvey in health care workers of the Veneto region. Clin Chem Lab Med 2020;58:2107-11.

24 Garcia-Basteiro AL, Moncunill G, Tortajada M, et al. Seroprevalence of antibodies against SARS-CoV-2 among health care workers in a large Spanish reference Hospital. Nat Commun 2020;11:3500.

25 Ali S, Noreen S, Farooq I, et al. Risk assessment of healthcare workers at the frontline against COVID-19. Pak J Med Sci 2020;36:COVID19-S99-S103. 